\title{
LOS MOVIMIENTOS REGIONALISTAS EN CHILE Y LA DESCENTRALIZACIÓN COOPTADA DEL BLOQUE EN EL PODER ${ }^{1}$
}

\author{
Regionalist movements in Chile and the ruling bloc's \\ co-optation of decentralization
}

\author{
FRANCESCO EMMANUEL PENAGLIA VÁSQUEZ \\ Universidad Alberto Hurtado \\ fpenaglia@uahurtado.cl \\ ESTEBAN MANUEL VALENZUELA VAN TREEK \\ Universidad Alberto Hurtado \\ evalenzu@uahurtado.cl
}

JESSICA LEGUÁ VALENZUELA

Universidad Alberto Hurtado

Jess.leg.val@gmail.com

Cómo citar/Citation

Penaglia Vásquez, F. E., Valenzuela Van Treek, E. M. y Leguá Valenzuela, J. (2018). Los movimientos regionalistas en Chile y la descentralización cooptada del bloque en el poder. Revista de Estudios Políticos, 179, 131-169. doi: https://doi.org/10.18042/cepc/rep. 179.05

\section{Resumen}

Este artículo está orientado a estudiar la mayor actividad de los movimientos regionalistas anticentralistas y antineoliberales en Chile desde el año 2011 y la resistencia del bloque en el poder por impulsar reformas orientadas a distribuir poder, elevar tributos y dictar normas de autogobierno. La investigación establece cómo el segundo Gobierno de Michelle Bachelet se ha hecho cargo de la agenda de los

1 Artículo realizado en el marco del proyecto FONDECYT 1150684, denominado «Movimientos regionalistas y transformaciones políticas en Chile 2011-2016: entre la cooptación y el poder autónomo». 
movimientos regionales. Para ello, en la primera sección se describe el escenario socio-político en Chile, caracterizado por el aumento de la conflictividad social en el ańo 2011; la emergencia de la coalición gobernante Nueva Mayoría con una retórica reformista, y la crisis de legitimidad política en Chile. Posteriormente, en la segunda sección se profundizará en los conflictos regionales y la estrategia del bloque en el poder para procesar esta conflictividad. Para ello se analiza cualitativa y cuantitativamente el tránsito (estrategia del bloque en el poder) mediante la agenda de los movimientos regionales a la agenda gubernamental, considerando como fase intermedia el trabajo de la Comisión Asesora Presidencial en Descentralización y Desarrollo Regional y los procesos de participación ciudadana que se desarrollaron en dicho proceso.

\section{Palabras clave}

Conflicto social; movimientos regionales; descentralización; neoliberalismo; transición en Chile.

\section{Abstract}

This article studies the main activities of the anti-centralist and anti-neo-liberal regionalist movements in Chile from 2011, and the resistance of the bloc holding political power to the promotion of reforms aimed at the distribution of powers, increases in taxation, and the establishment of norms of self-government. The investigation refers to the co-optation of the agenda of regionalist movements by the second national government of Michelle Bachelet. The first section describes the socio-political context in Chile, characterised by an increase in social conflict starting in 2011, the rise of the Nueva Mayoria as a ruling coalition accompanied by reformist rhetoric, and the crisis of political legitimacy in Chile. The second section examines regional conflicts and the strategy of the governing bloc to deal with them. Finally, the article provides a qualitative and quantitative analysis of the transition (the strategy of the governing bloc), and the co-opting of the agendas of the regionalist movements to the governmental agenda, considering as an intermediate stage the work of the Comisión Asesora Presidencial en Descentralización y Desarrollo Regional and the processes of citizens' participation that were developed.

\section{Keywords}

Social conflict; regional movements; descentralization; neoliberalism; transition in Chile. 


\section{SUMARIO}

I. INTRODUCCIÓN. II. LA CONCERTACIÓN: AUGE Y CAÍDA: 1. Del rechazo a Pinochet a la consolidación de su modelo. 2. Las disputas intragrupo: autocomplacientes vs. autoflagelantes. 3. Minoría descentralizadora, cooptación autoritaria y descentralización. III. LA CONFLICTIVIDAD SOCIAL Y LAS PROTESTAS: LA INFLEXIÓN (2011): 1. El estallido: del malestar a las protestas. 2. La conflictividad regional: una demanda de carácter histórico: 2.1. Calama: alto precio del cobre sin beneficios en el territorio. 2.2. Aysén: politización reformista ascendente y redes transversales. 2.3. Magallanes: una identidad histórica de lucha. IV. LA RESPUESTA DEL BLOQUE EN EL PODER: 1. La Concertación siente el golpe y busca reconstruirse: el origen de la Nueva Mayoría y la respuesta a los conflictos regionales. 2. La inclusión de las demandas ciudadanas en la agenda gubernamental de Bachelet. V. REFLEXIONES FINALES: ANÁLISIS GLOBAL DE LOS RESULTADOS. BIBLIOGRAFIA.

\section{INTRODUCCIÓN}

La Concertación de Partidos por la Democracia (en adelante Concertación), coalición dominante en Chile en el periodo postdictatorial, sufrió a lo largo de su historia múltiples tensiones entre grupos conservadores "de orden» denominados «autocomplacientes», y grupos socialdemócratas denominados «autoflagelantes». Para los primeros, el modelo económico y político en Chile — heredado de la Dictadura - era exitoso debido a que daba estabilidad, crecimiento y gobernabilidad, por esta razón, solo se requería de ajustes menores. En tanto, los segundos cuestionaban el neoliberalismo desregulado, la baja capacidad de implementar reformas, el excesivo diálogo y consenso con la derecha chilena y la construcción de un régimen poco democrático.

Las disputas intra Concertación siempre tuvieron como triunfadores a los grupos «autocomplacientes», razón por la que, tras veinte ańos en el Gobierno, la coalición no implementó cambios sustantivos en las dos «almas» del modelo pinochetista: modelo económico y Constitución política. Es en este contexto cuando, durante los años 2010-2013, se evidenció un divorcio entre el bloque en el poder y el pueblo en tres aspectos clave. En primer lugar, destaca la derrota electoral de la Concertación en las elecciones presidenciales, provocando el retorno de la derecha al poder político desde 1990 con Pinochet, y desde 1964 con Alessandri victorioso en las elecciones de 1958. Por otra parte, los estudios evidencian una expansión significativa de protestas 
desde el año 2011, principalmente, en torno a cuatro matrices conflictivas: a) estudiantil, b) ambiental, c) territorial-regionalista, y d) agudización del conflicto mapuche. Finalmente, el periodo muestra un desprestigio generalizado de las coaliciones y partidos políticos, crisis de las instituciones, desafección, crisis de representatividad, divorcio entre lo social, lo político y la política, entre otros fenómenos evidenciados en todos los estudios y encuestas de opinión desde 1997, pero exacerbados en los últimos años.

Es en este escenario que la otrora Concertación, rebautizada «Nueva Mayoría» luego de incorporar al Partido Comunista a la coalición, se propuso conducir nuevamente al país con Michelle Bachelet a la cabeza en lo que denominaron un «nuevo ciclo». De este modo, elaborando un programa «autoflagelante» con los contenidos, Bachelet, en su segundo periodo presidencial, 2014-2017, proponía dar una solución a los temas pendientes en los primeros veinte años de la Concertación profundizando reformas en lo que Manuel Antonio Garretón (2013) llama «neoliberalismo corregido, progresismo limitado».

El presente artículo analizará cómo el Gobierno de la nueva mayoría procesó los conflictos regionales chilenos y las demandas ciudadanas territoriales, buscando indagar si la agenda descentralizadora estuvo orientada a la cooptación autoritaria con énfasis en el orden (siguiendo el modelo concertacionista transicional), o la agenda estuvo orientada en una perspectiva de transformación, siguiendo la lectura de un "nuevo ciclo» (modelo declarado por la nueva mayoría). Para ello, se estudiarán dos factores claves: 1) la trayectoria, fases del procesamiento de conflicto y la estrategia de la nueva mayoría para hacerse cargo de la conflictividad regional a partir del nombramiento de la Comisión Asesora Presidencial en Descentralización y Desarrollo Regional (en adelante Comisión); y 2) el grado de integración de las demandas de los movimientos a la agenda gubernamental.

El estudio se propone la comparación de cuatro momentos: 1) la fase de conflicto de los movimientos con la construcción de demandas regionales; 2) la fase de diálogos ciudadanos o cabildos territoriales en cada región, donde la ciudadanía expresó sus demandas; 3) la fase de propuestas de la Comisión en la que los miembros, tomando como insumo los «diálogos regionales», elaboraron propuestas para entregar a la presidenta; 4) la fase de agenda gubernamental, en la que el Gobierno ha tomado - $\mathrm{o}$ no- como insumo las propuestas de la Comisión para construir su propia agenda legislativa.

La hipótesis central del estudio es que, pese al discurso aparentemente «renovador» de la Nueva Mayoría, en lo que respecta a descentralización se ha impuesto la visión concertacionista «autocomplaciente» de orden, deteniendo un proceso descentralizador profundo y realizando reformas orientadas a administrar el conflicto social en una apuesta cooptativa autoritaria. 


\section{LA CONCERTACIÓN: AUGE Y CAÍDA}

\section{DEL RECHAZO A PINOCHET A LA CONSOLIDACIÓN DE SU MODELO}

En 1986, el descubrimiento de armas en Carrizal Bajo y el fallido atentado a Pinochet realizado por el Frente Patriótico Manuel Rodríguez marcaron el declive de los proyectos de sublevación y rebelión popular de masas. El «año decisivo», que estuvo orientado a impulsar una Guerra Patriótica Nacional para derrotar a la dictadura, fracasó sepultando definitivamente al Movimiento Democrático Popular ${ }^{2}$ y consolidando la posición de la Alianza Democrática. Esta última coalición de partidos —iniciada en 1983- terminó conduciendo el proceso democratizador, generando un extenso diálogo con el régimen militar y concluyendo con una transición pactada, la que para Hidalgo (2011: 63) favoreció al régimen tanto en la legitimación de la Constitución de 1980 como en las instituciones de democracia protegida y Ley de amnistía.

De esta manera, la Concertación de Partidos por la Democracia ${ }^{3}$-en adelante Concertación-, formada desde los cimientos de la Alianza Democrática, fue la coalición triunfadora en el plebiscito de 1988, ganando posteriormente las elecciones en diciembre de 1989. Con ello, se inició un periodo transicional (o postdictatorial) marcado por la continuidad del modelo económico y político de la dictadura en:

1. Continuidad y profundización del modelo neoclásico de Chicago. Si bien el «neoliberalismo» fue impuesto desde mediados de la década de los ańos setenta en Chile 4 . El modelo fue consolidado durante la década de los noventa, siguiendo las tendencias latinoamericanas del Consenso de Washington a través de las reformas de primera y segunda

2 Conformada por sectores del Movimiento de Acción Popular Unitaria (MAPU), Movimiento de Izquierda Revolucionaria (MIR), Izquierda Cristiana, Partido Comunista y Partido Socialista Almeyda.

3 Conformada por en sus orígenes por la Democracia Cristiana, Partido Socialista, Partido Radical, Partido por la Democracia, Partido Socialdemocracia Chilena, Partido Humanista, Los Verdes y Partido Alianza de Centro.

4 Tanto a partir de la reducción del gasto fiscal, la privatización de 725 empresas, liberación y desregulación tributaria, laboral, sectores económicos, divisas, aranceles (Dávila y Penaglia, 2012) como con la destrucción del incipiente «Estado benefactor» a través de la reforma a la seguridad social (sistema de pensiones, privatización de la salud), cambios en la legislación sindical y negociación colectiva, desregulación y mercantilización de la educación, entre otros. 
generación impuestas por el Banco Mundial y el Fondo Monetario Internacional a cambio de financiamiento (e.g.: García, 2003; Andara, 2007; Santiso, 2001).

2. Continuidad del orden institucional, enclaves autoritarios y cerrojos institucionales (Garretón, 2003, y Fernández, 2002) heredados de la dictadura y la Constitución del $1980^{5}$, así como enclaves propios de la transición.

Para Manuel Antonio Garretón (2009: 102) la existencia de una democracia limitada o incompleta se encuentra en la vigencia de la constitución de 1980 y la institucionalidad política que de ella se deriva, generando un empate entre "fuerzas de la dictadura» $y$ «fuerzas democráticas» en todas las instituciones políticas relevantes.

Sin embargo, al igual como ocurrió en el ámbito económico —en el que la transición profundizó el modelo-, en el ámbito político institucional el régimen se consolidó a través de «acuerdos» que habrían dado paso a la existencia de "enclaves transicionales» (Garretón, 2009: 102). Estos enclaves, para Siavelis (2009), contemplaron: 1) Cuoteo (distribución de poder institucional como botín por acuerdos entre partidos); 2) Control de la élite en la selección de candidatos y la política electoral; 3) Dominación de los partidos en la política (de partidos con baja adhesión popular); 4) Formulación de políticas elitistas y extrainstitucionales; 5) Intocabilidad del modelo económico. En la primera década del retorno a la democracia, la derecha controló el Senado por la vía de ocho senadores designados, incluyendo los excomandantes de las fuerzas armadas.

El modelo postdictatorial, gobernado por la Concertación durante veinte años, estuvo marcado por una renuncia a las ideas de transformación motivadas por la renovación socialista (Isner, 2004; Valenzuela, 2014), y un fuerte ideal de orden y estabilidad ${ }^{6}$. Es decir, en términos politológicos fue continuadora de los

5 Fernández (2002) define a los enclaves autoritarios como: 1) Rol garante del orden institucional de las FF.AA. y Carabineros; 2) Inamovilidad de los comandantes en jefe; 3) Atribuciones del Consejo de Seguridad Nacional. En cuanto a los cerrojos institucionales destacaban: 1) Senadores designados no elegidos democráticamente; 2) Sistema binominal mayoritario que genera empate; 3) Quórum supra mayoritarios de $3 / 5$; 4) Tribunal constitucional antidemocrático con capacidad de anular reformas legales del congreso; 5) Ausencia de mecanismos populares constituyentes. Si bien algunos de estos enclaves y cerrojos institucionales han sido reformados en los últimos veinticinco años, muchos continúan vigentes.

6 Orden y estabilidad que para Ortiz (2015a) no escatimó en utilizar la violencia y represión tanto con el uso de aparatos de inteligencia a través de la «oficina» como en 
principios de gobernabilidad conservadora de la Comisión Trilateral (Monedero, 2012; Camou, 2010). Esto quiere decir, énfasis en crecimiento económico, bajos niveles de democracia y participación, y éxito institucional sustentado en estabilidad y ausencia de conflicto.

Por pragmatismo o convicción, la renuncia $-\mathrm{o}$ imposibilidad - de generar transformaciones al modelo dictatorial generó una escisión entre Estado y sociedad (pueblo, demos). De este modo, si, como describe Garretón (2013), desde 1930 a 1973 los partidos políticos tenían representación y expresión de intereses de clases, a la vez que canalizaban efectivamente esas expresiones en el sistema político, durante la transición esa "correa de transmisión» dejó de funcionar, bifurcando lo social de la política. Con lo anterior, el tejido social, la asociatividad y la construcción popular generada en dictadura desde 1983 — con las protestas, ollas comunes, comprando juntos y otros espacios de organización que incluían también ONGs, medios de comunicación y centros de pensamiento — fueron ignorados y — en cierta medidadespotenciados durante la transición.

Un sistema político que apuntaba al orden era disfuncional respecto a un tejido social politizado, por lo que la relación entre el Estado y la sociedad civil, cuando no era cooptada y clientelar (Durston, 2012; Valenzuela, 2015), fue reemplazada por enfoques de nueva gestión pública donde la participación popular fue modificada por espacios de consulta en múltiples ventanillas del Estado, hiperfragmentados y en un enfoque ciudadano-cliente que permitía «conocer» la demanda para focalizar el gasto público y hacerlo más eficiente (Penaglia, 2013). Bajo este enfoque promovido por organismos internacionales, el pueblo ahora se denominaba capital social, y el poder popular, gobernanza y accountability.

\section{LAS DISPUTAS INTRAGRUPO: AUTOCOMPLACIENTES VS. AUTOFLAGELANTES}

No obstante lo anterior, el periodo concertacionista no estuvo exento de tensiones internas, las que resolvió con la imposición del orden conservador. Los primeros dos hitos que marcan un giro respecto a la crítica intra Concertación ${ }^{7}$ estuvieron marcados por los aportes de Tomás Moulian en 1997 y el

asesinatos dudosos realizados por carabineros desde la masacre de Apoquindo, pasando por la muerte de decenas de mapuches hasta llegar al asesinato reciente de trabajador Nelson Quichillao en julio de 2015.

7 La crítica de sectores de izquierda fuera de la Concertación — aunque invisibilizados o marginales - nunca dejó de existir 
Programa de las Naciones Unidas para el Desarrollo 1998 (PNUD 1998), coordinado por Norbert Lechner.

Para Tomás Moulian en "Chile Actual: Anatomía de un Mito», la «transición» se construyó en un sistema de trueques que generó estabilidad a cambio de silencio. Para ello, la Concertación desarrolló el «blanqueo» del proyecto pinochetista con un realismo «frío y soberbio» que creía interpretar las necesidades de Chile, lo que implicaba la legitimación del orden político y económico.

Por otro lado, el segundo informe desarrollado en Chile por el PNUD tuvo un gran impacto académico y político. El foco central del informe detalla que, si bien Chile ha alcanzado significativos avances a nivel económico, las personas y sus relaciones sociales se han visto debilitadas aumentando su desconfianza y malestar, lo que propiciaría un terreno fértil para el conflicto.

En materia de subjetivación, el informe señala que los chilenos se encuentran atravesados por tres temores: el temor al otro, a la exclusión y al sinsentido. Lo que serían factores que inciden en «la confianza en los otros, el sentido de pertenencia y las certidumbres que ordenan el mundo de la vida cotidiana» (PNUD, 1998: 19).

Por otro lado, el «miedo al otro» habría potenciado las inseguridades debilitando el vínculo social y el sentido de comunidad. "El «nosotros», es decir, la identidad, la confianza y la sociabilidad, se habría resquebrajado [...] se restringe cada vez más a los círculos íntimos de familiares y amigos. Lo público aparece como un espacio ocupado por un «otro» anónimo y, a veces, amenazador» (PNUD, 1998: 24).

Con la emergencia de los antecedentes empíricos y normativos que cuestionaban el «éxito» del modelo transicional, las disputas políticas al interior de la Concertación se hicieron cada vez más recurrentes, principalmente potenciadas, como señala Méndez (2015), por los resultados de las elecciones parlamentarias de 1997 que evidenciaron los primeros síntomas de una crisis de representatividad y abstencionismo. Esto dio paso a una confrontación que fue mediáticamente conocida como «autocomplacientes» vs. «autoflagelantes».

Para los autocomplacientes, que expresaron sus ideas en el documento «Renovar la Concertación. La Fuerza de Nuestras Ideas» en mayo del 1998, la transición liderada por la Concertación fue una de las etapas «más promisorias de la historia de Chile» por conseguir la «libertad», controlar la acción «terrorista» y a las FF. AA. y, principalmente, por consolidar un modelo económico virtuoso. Respecto a esto último, este grupo de la Concertación hizo suyos los principios de la economía neoclásica. El documento enfatiza en la tesis del "chorreo» sosteniendo que el crecimiento económico ha generado progreso, mayor equidad social y reducción de la pobreza. De esta forma, el manifiesto señala: «somos partidarios sin vacilaciones de una moderna economía de 
mercado» (1998: 9), agregando que el Estado debe tener un rol limitado en tareas esenciales (Estado mínimo). Con ello el texto abraza el proyecto del Estado subsidiario impuesto a «sangre y fuego» (Salazar y Pinto, 1999) en la Constitución dictatorial, argumentando que «el Estado debe ser un impulsor decidido y eficaz de soluciones que el mercado por sí solo es incapaz de generar» (1998: 13).

La respuesta de los «autoflagelantes» no se hizo esperar y se estructuró en el documento «La gente tiene razón: reflexiones sobre las responsabilidades de la Concertación en los tiempos presentes» (junio de 1998) (Ominami, 2009). El texto, si bien está lejos de hacer una crítica al modelo capitalista y releva el rol de la Concertación durante el periodo, destaca también la necesidad de «retornar a las convicciones». Crítica al texto autocomplaciente acusándolo de poseer «excesivo exitismo en su evaluación de lo ya hecho, de errores en su diagnóstico de las causas del malestar que detecta y, sobre todo, insuficiencia en la definición de las tareas futuras» (1998: 2). El texto cuestiona el modelo económico y político dictatorial y el impacto que ha producido en lo cultural y social, debilitando los lazos y vínculos colectivos. Releva los éxitos «indiscutibles» de la transición, sin embargo, admite errores y omisiones del proceso, tales como la vigencia de la Constitución, la difícil subordinación de las FF. AA. al poder civil y principalmente - a diferencia del texto autocomplaciente- evidencia que la desigualdad es una de las tareas claves pendientes, sosteniendo que:

La evolución política, económica y cultural del país muestra, también, fuertes y notorias asimetrías entre estas dimensiones provocadas por la presencia de importantes desigualdades y privilegios. Entre otros hechos, la relación entre crecimiento económico y equidad no aparece satisfactoria para los valores e ideales que han iluminado el mundo político cultural del conjunto de los actores que forman parte de la Concertación. El país presenta altas tasas de concentración del patrimonio y del ingreso, mientras que por otro lado se percibe un estancamiento de las posibilidades de movilidad social y la participación política de numerosos sectores de la población (1998: 6).

El documento concluye con que el crecimiento económico no es el único camino hacia el desarrollo, que existe una democracia incompleta y que es necesario avanzar hacia una "soberanía real».

Estas tensiones se extenderían durante la década, lo que sumado a los efectos de la crisis asiática, llevarían a la Concertación al borde de la derrota electoral en 1999, teniendo Ricardo Lagos una estrecha victoria de 3 puntos en segunda vuelta ante Joaquín Lavín. Como sostiene Eugnio Tironi: «Ricardo Lagos tuvo que dar un giro ostensible a su campaña, evitando los aspectos 
conflictivos y enfatizando los contenidos, liderazgos y estilos más clásicamente centristas, para reforzar la noción de que su Gobierno sería el tercero de la Concertación y no el segundo socialista después del de Salvador Allende» (2002: 32).

Sin duda, Ricardo Lagos, lejos de ser un presidente con orientación socialista, o a lo sumo «autoflagelante», orientó su política hacia la profundización del orden económico construido por la dictadura. Durante su mandato fueron privatizadas áreas de CODELCO, se permitió el endeudamiento bancario como política de financiamiento estudiantil universitario (CAE), se concesionaron la gran mayoría de las carreteras, entre otras medidas. A su vez, desde lo político institucional, Lagos, en el año 2005, legitimó la Constitución pinochetista firmándola como una "nueva Constitución». En su discurso señaló: "[...] hoy contamos con una Constitución que ya no nos divide», pese a tratarse solo de algunas reformas constitucionales como la eliminación de senadores designados y vitalicios y el acortamiento del periodo presidencial de 6 a 4 años (Atria, 2013). A pesar de estas reformas, en lo sustantivo, esta «nueva Constitución» mantenía íntegro el proyecto dictatorial en cuanto a enclaves autoritarios y visión doctrinal.

En este mismo periodo, a nivel interno del Partido Socialista en el XXVII Congreso del año 2005, se produciría lo que Edison Ortiz (2015b) denomina "Golpe Blanco", que implicó la salida de Gonzalo Martner de la Presidencia del Partido, la derrota del "progresismo" dentro del PS y su posterior rol de «orden» en alianza con la Democracia Cristiana. Este hito sería la última victoria «autocomplaciente», manteniendo una Concertación unida, ya que durante el primer periodo presidencial de Bachelet comenzaron a emerger diputados "díscolos», quienes finalmente terminaron rompiendo con la Concertación, al igual que el senador Alejandro Navarro. Esto se tradujo en que, en las elecciones 2009-2010, además de Eduardo Frei como candidato oficial de la Concertación, se levantaran las candidaturas de Jorge Arrate $(6,21 \%$ de los votos) y Marco Enrique-Ominami (20,14\% de los votos), ambos exmilitantes socialistas. Finalmente, esas elecciones fueron ganadas por Sebastián Pińera, terminando el ciclo concertacionista y marcando el regreso de la «derecha» al poder.

\section{MINORÍA DESCENTRALIZADORA, COOPTACIÓN AUTORITARIA Y DESCENTRALIZACIÓN}

La discusión sobre descentralización ha sido una de las dimensiones políticas atravesada por el debate entre autocomplacientes (orden) y autoflagelantes (democratización y cambio), en el que una parte promovió mayor devolución de poder y otra se mantuvo en el tradicional centralismo paraestatal (Valenzuela, 
1999). En este periodo, dentro de sectores autoflagelentes se comenzaron a constituir apuestas como Los Federales (con un segmento de políticos e intelectuales de centro-izquierda junto a sectores de derecha liberal), a partir de donde empezaron a posicionar la necesidad de superar el excesivo centralismo anclado en el ideario de orden transicional y el miedo al poder territorial. Este grupo, entre otras cosas, criticó: las autoridades designadas por el poder central, la ausencia de recursos autónomos, la inexistencia de competencias y la falta de controles y mecanismos de participación.

La irrupción de Los Federales ocurre cuando Ricardo Lagos no cumple sus compromisos de campaña en la materia, tales como elección de ejecutivo regional, consejeros regionales y creación de Gobiernos metropolitanos. Por estos motivos Los Federales realizaron treinta campańas y acciones de protesta reclamando equiparidad de recursos para las regiones y políticas respecto a lo que se daba en la Región Metropolitana.

Si bien en los inicios de la transición sectores de la Democracia Cristiana y Arturo Valenzuela promovieron un cambio de régimen político hacia uno de carácter semipresidencial y descentralizado, estos actores fueron teniendo cada vez menos cabida en el desarrollo programático de la Concertación, donde prácticamente no hubo avances en la materia. El trabajo de Rodrigo Mardones (2008) da cuenta de ello al analizar el bajo impacto de las 122 leyes en descentralización desarrolladas durante el periodo 1990-2008. En materia de competencias, la mayoría son aspectos regulatorios en torno a delegación de funciones "con impacto marginal en términos de descentralización»; en cuanto a descentralización política, se regularon aspectos menores como la formación de coaliciones; y en el ámbito fiscal, principalmente «estuvieron dirigidas a resolver déficit de salud y educación municipal».

De este modo, durante la transición se forjó un municipio mínimo, sin poder en rentas locales regionales ni en la planificación. Con ello, Chile es uno de los países más centralistas de la OCDE y América Latina, lo que se refleja entre otras cosas en que el gasto subnacional autónomo sea del $15 \%$ versus el $25 \%$ de promedio de América Latina y el $40 \%$ de la OCDE (Rosales et al., 2012). El país no cuenta con gobiernos metropolitanos y es el único país sudamericano que no elige gobernadores regionales. De esta forma, el Gobierno central administra el territorio cooptando a través de distintos mecanismos la conflictividad, sea secuestrando las demandas ciudadanas con dádivas (Haldenwang, 1990), combinando leyes centrales para legitimar el poder junto con la represión (Gerschewski, 2010), así como integrando disidentes al poder (Selznick, 1994).

Por otra parte, John Durston (2012) concluyó la fuerte incrustación de las redes clientelares en la década 1999-2009 en la manipulación de la inversión pública de las regiones de la Araucanía, Bío-Bío y Coquimbo, constatando 
la existencia de tres mecanismos: 1) el caudillo que ofrece puestos de trabajo y consigue proyectos; 2) el broker que intermedia una red de favores entre políticos y comunidades; el gestor, que construye legitimidad local a partir del lobby en favor de proyectos comunitarios (Durston, 2012: 375).

\section{Tabla 1. Rasgos entre modelo cooptador-discrecional versus modelo democrático-descentralizador}

\begin{tabular}{|c|c|c|}
\hline Modelo / rasgo & Cooptador-Discrecional & Democrático-Descentralizador \\
\hline $\begin{array}{l}\text { Régimen y } \\
\text { sistema político }\end{array}$ & $\begin{array}{l}\text { Centralista, presidencialista, } \\
\text { con débiles instituciones y } \\
\text { alta discrecionalidad en el } \\
\text { nombramiento de personal y en la } \\
\text { asignación de contratos, sistemas } \\
\text { electorales que favorecen grandes } \\
\text { partidos/coaliciones hegemónicas y } \\
\text { existencia de un alto peso de grupos } \\
\text { económicos aliados al poder político } \\
\text { o de las empresas públicas. }\end{array}$ & $\begin{array}{l}\text { Poder parlamentario como } \\
\text { contrapeso, descentralización, } \\
\text { sistema electoral proporcional, } \\
\text { separación de poderes, control } \\
\text { de legalidad, alta dirección } \\
\text { pública, autonomías indígenas y } \\
\text { territoriales, limitación aportes } \\
\text { privados a política, sistemas } \\
\text { de consejos para decisiones, } \\
\text { modelos participativos de } \\
\text { asignación de recursos. }\end{array}$ \\
\hline $\begin{array}{l}\text { Relación formal } \\
\text { con grupos } \\
\text { subnacionales }\end{array}$ & $\begin{array}{l}\text { Fondos discrecionales para negociar } \\
\text { con grupos críticos, bonos de } \\
\text { término de conflicto, posibilidad } \\
\text { de leyes especiales, creación de } \\
\text { comisiones de estudios, posibilidad } \\
\text { de nombramientos de opositores } \\
\text { en cargos de la administración y en } \\
\text { la coalición o partido gobernante, } \\
\text { amnistías. }\end{array}$ & $\begin{array}{l}\text { Leyes de resolución de } \\
\text { controversias, sistema de } \\
\text { mediación, leyes nacionales de } \\
\text { impactos locales, negociaciones } \\
\text { colectivas y poder sindical. }\end{array}$ \\
\hline $\begin{array}{l}\text { Corrupción } \\
\text { informal }\end{array}$ & $\begin{array}{l}\text { Comisiones (coimas), contratos } \\
\text { especiales, contratación de } \\
\text { familiares, entrega de tierras, } \\
\text { contratos o servicios. }\end{array}$ & $\begin{array}{l}\text { Contraloría independiente, } \\
\text { carrera profesional, } \\
\text { limitaciones al nepotismo, } \\
\text { licitaciones controladas, baja } \\
\text { discrecionalidad, cultura cívica } \\
\text { de control ciudadano. }\end{array}$ \\
\hline $\begin{array}{l}\text { Neutralización } \\
\text { sutil }\end{array}$ & $\begin{array}{l}\text { Reconocimiento retórico, } \\
\text { premiaciones, nombramiento en } \\
\text { comisiones especiales, protagonismo } \\
\text { en medios oficiales. }\end{array}$ & $\begin{array}{l}\text { Consejos plurales para premios, } \\
\text { comisiones por instituciones (no } \\
\text { personales), libertad de medios } \\
\text { de comunicación. }\end{array}$ \\
\hline
\end{tabular}

Fuente: Valenzuela y Yévenes, 2015. 
Por su parte, en el tema específico de la cooptación y descentralización, Valenzuela y Yévenes (2015) identifican cuatro mecanismos: 1) estructurales vinculados al marco jurídico institucional y al régimen político; 2) formales, que tienen que ver con procedimientos administrativos que favorecen espacios discrecionales en la toma de decisiones; 3) informales (fuera de la legalidad), como las coimas o contratos privilegiados; y 4) sutiles, entre los que cuentan «reconocimiento retórico, premiaciones, nombramiento en comisiones especiales, protagonismo en medios oficiales». A partir de ello, los autores proponen una comparación entre un modelo centralista-cooptativo y otro democrático-descentralizador, lo que marca algunas de las principales diferencias al interior del bloque en el poder en la materia.

\section{LA CONFLICTIVIDAD SOCIAL Y LAS PROTESTAS: LA INFLEXIÓN (2011)}

\section{EL ESTALLIDO: DEL MALESTAR A LAS PROTESTAS}

En 2011 se vivió una inflexión sociopolítica en la que se manifestó un descontento social que, sin haber provocado aun un cambio en el orden político económico, se ha prolongado en una crisis de la política y una activación de las acciones colectivas. En este contexto, en Chile emergió una pluralidad de conflictos que se constituyeron tanto desde proyectos con vocación de transformaciones estructurales hasta matrices conflictuales demandantes del Estado por la reproducción social, integración y/o cambio institucional.

En este contexto, es posible agrupar la conflictividad en torno a cuatro grandes matrices y relatos:

— La lucha por derechos sociales básicos, eje caracterizado principalmente por el movimiento estudiantil desde el 2006 a la fecha, pero en el que en 2016 se integra la lucha por el sistema de pensiones y la incipiente articulación en torno a la salud.

— La radicalización del conflicto etnonacional y territorial mapuche, que si bien tiene centenares de años, y en el mediano plazo se agudizó desde mediados de los ańos noventa, estudios como el de Rojas y Miranda (2016) evidencian una radicalización en los repertorios de lucha desde el 2011.

- Conflictos territoriales-ambientales en los que se tensiona el capitalismo extractivista con las comunidades locales, como los casos de 
Pascua Lama 2005-2006, 2013, Mehuin 2006, Caimanes 2010, Castilla 2010, Hidroaysén 2011, Freirina 2012, Chiloé 2016.

- Conflictos regionalistas caracterizados por reivindicaciones y demandas de zonas, generalmente, extremas, que tienen como uno de los ejes articuladores el centralismo y la ausencia de poder político para decidir sobre temas regionales como los casos de Calama 2010-2013, Magallanes 2011, Aysén 2012, Arica 2013, Tocopilla 2012.

En este escenario, gran parte de las ciencias sociales nacionales estuvo dirigida a indagar qué estaba ocurriendo, caracterizando mayoritariamente el periodo como una inflexión respecto a la abulia social de los años noventa y 2000. No obstante lo anterior, pese a haber existido cierto acuerdo en torno al «despertar social» u «hora de la politización», como le llamó el informe del PNUD 2016, las explicaciones de las ciencias sociales de desenvolvieron por caminos distintos: proyectos refundacionales de las instituciones políticas, institucionales (Garretón, 2012); proyectos autónomos-extra institucionales, sociocráticos, de base popular y críticos al neoliberalismo (Mayol, 2012; Salazar, 2013; Gaudichaud, 2015); demandas por la integración al modelo de desarrollo capitalista (Tironi, 2011), entre otros.

Los datos son claros, como muestra el gráfico 1, mientras en 2009 existieron 1773 manifestaciones en Chile, esa cifra se casi cuadruplicó en 2011, llegando a 6938.

Gráfico 1. Número de manifestaciones en Chile

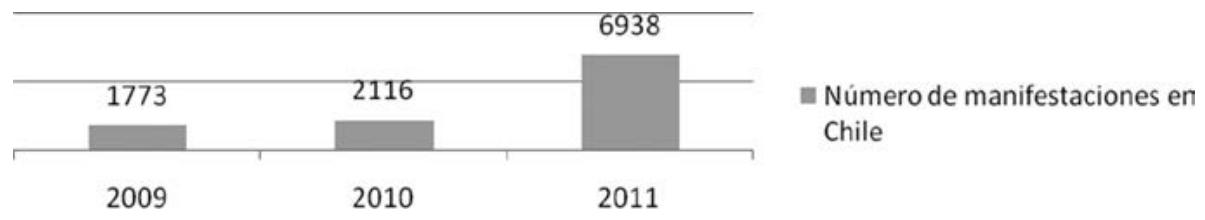

Fuente: PNUD (2012: 41).

Lo mismo ocurrió con las alteraciones del orden público, que, como muestra el gráfico 2, aumentaron en 9 veces entre el 2009 y el $2011^{8}$.

8 Es importante agregar que las cifras de los gráficos 1 y 2 fueron construidas en base a los datos oficiales de Carabineros y el Ministerio del Interior, por lo que no necesariamente representan el número total de episodios y participantes. Los organizadores de las movilizaciones siempre difieren de los números oficiales; por 


\section{Gráfico 2. Participantes en alteraciones al orden público}

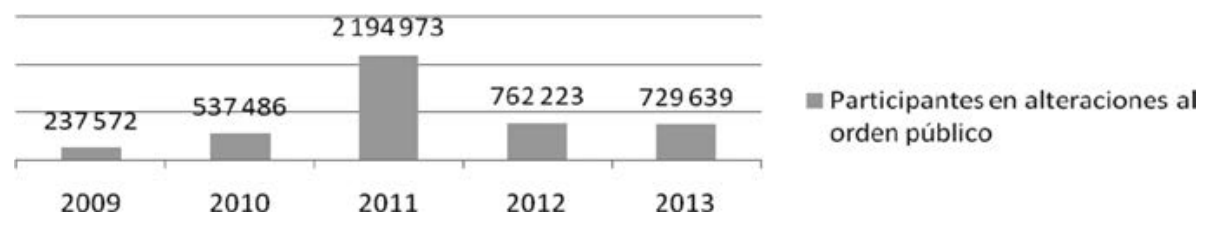

Fuente: PNUD (2014: 253).

De este modo, como señaló el historiador Mario Garcés, «algo pasó en Chile» que quebró lo que se creía un país con el orden social mejor logrado y naturalizado (2012: 7). Este quiebre y aumento en la conflictividad y ruptura del orden como valor central de la sociedad (Mayol, 2013) significó también una proliferación de interpretaciones en el campo político y académico, que, salvo algunas excepciones de intelectuales de derecha (Oppliger y Guzman, 2012), compartían en describir el fenómeno como una inflexión.

\section{LA CONFLICTIVIDAD REGIONAL: UNA DEMANDA DE CARÁCTER HISTÓRICO}

En el marco del estallido de conflictos sociales, una de las expresiones colectivas que mayor relevancia ha tenido desde el 2011 son los movimientos regionales. Esta matriz conflictual no es nueva en la historia de Chile. Desde 1830 el modelo portaliano y conservador del «peso de la noche» impuso un sistema político rígido, autoritario y centralista, a beneficio exclusivo del patriciado mercantil de Santiago. De esta forma, el proyecto nacional (de la élite santiaguina) buscó imponer la idea de nación homogénea. Con ello, la «chilenidad", construida a través de guerras y del rol de la escuela, se orientó a eliminar las diferencias étnicas, de clase y territoriales en pos de un proyecto unificador hegemónico. Las élites centralistas, con el miedo a la diversidad y a la «anarquía», buscaron destruir los espacios de participación social y comunitaria, constituyente, regionalista y diversa.

No obstante lo anterior, pese a las estrategias de cooptación, clientelización y represión, fueron numerosas las veces en las que el modelo «unitario» entró en crisis a través de diversos motines. De este modo, en la historia de Chile es posible identificar diversas crisis nacionales, 1823, 1829, 1851, 1859,

ejemplo, en la marcha del 16 de abril de 2015, Carabineros cifró en 40000 los asistentes y los organizadores en 180000 . 
1891 y 1927 (Salazar, 2011; Valenzuela, 1999), en las que se ha cuestionado la matriz centralista.

Con ello, las demandas por autonomía territorial son una demanda latente. De esta forma, no resulta extraño que algunos estudios de opinión', como el Barómetro de la Universidad de los Lagos en 2011 en tres regiones del país, más del $86 \%$ de los encuestados consideraba insuficiente la autonomía regional, mientras que sobre el $90 \%$ de los encuestados estuvo de acuerdo o muy de acuerdo con la elección de intendentes y que las regiones tomaran sus decisiones o administrar su recaudación fiscal. A su vez, en el Barómetro a nivel nacional del 2009 , el $86,1 \%$ de los encuestados señalaba como importante la descentralización, el $80,1 \%$ que esta mejora la calidad de vida y el $72,5 \%$ demostró sentir una percepción de baja autonomía (Thayer, 2011).

Es en este contexto que durante el periodo 2011-2013 se alzaron una seguidilla de conflictos regionales cuestionadores del modelo centralista-extractivista. De este modo, si bien los casos de movimientos territoriales en el país son variados, el estudio ha buscado enfatizar en tres casos emblemáticos: Aysén, Magallanes y Calama, en base a los siguientes criterios: 1) acciones colectivas que lograron entablar discursos regionalistas, 2) acciones con grados de estabilidad, procesos de socialización y articulación definidos, 3) acciones colectivas con episodios conflictivos relevantes (paros, cortes de ruta, marchas), 4) acciones colectivas con presencia y relevancia mediática a nivel nacional. El anexo 1 detalla una síntesis de los principales movimientos del periodo 2011-2013.

\subsection{Calama: alto precio del cobre sin beneficios en el territorio}

El movimiento de Calama es uno de los casos emblemáticos de privación relativa y crisis de expectativas intraterritorial, motivados por el auge en el precio del cobre y los bajos beneficios que genera este para la región (Penaglia y Valenzuela, 2014). Ya en el año 2009 se estaba conformando el primer cabildo abierto, que posteriormente dio paso a las primeras manifestaciones en la ciudad, reivindicando el restablecimiento de los principios de la ley 11.828 derogada por la dictadura, que obligaba a dejar parte de las utilidades mineras en las comunas, favoreciendo el desarrollo local.

Las demandas principales del movimiento fueron: 1) la recuperación del $5 \%$ de las utilidades del cobre en zonas productoras; 2) compensación por el

9 Además de los estudios desarrollados por la Universidad de los Lagos con los aportes de investigadores como Gonzalo Delamaza y Eduardo Thayer, no existen estudios cuantitativos nacionales regulares y continuos sobre el tema de descentralización. 
traslado del campamento de Chuquicamata a Calama; 3) declarar a Calama Zona Extrema; 4) compensar con 400 millones de dólares por los 34 años en que la ciudad no cuenta con las utilidades del cobre; 5) renacionalización del cobre y agua.

Ante las respuestas insatisfactorias del Gobierno, desde la fecha en Calama se han desarrollado distintas manifestaciones y paros regionales durante más de tres años, bajando su intensidad en el segundo Gobierno Bachelet, tanto por la baja del precio de la libra de cobre a la mitad de su valor (de cuatro dólares la libra en el año 2012 a dos en el 2015), la incorporación del Partido Comunista al Gobierno y la esperanza que abrió la Comisión de Estado para la Descentralización (Troncoso, 2016).

\subsection{Aysén: politización reformista ascendente y redes transversales}

El conflicto en Aysén se desató en un contexto de descenso en la industria del salmón y de la pesca, agravado en febrero del año 2012 con la promulgación de la ley de pesca, lo que provocó el malestar de los pescadores que, junto a dirigentes de la zona, desataron las manifestaciones en la región.

Entre las demandas más importantes que desarrolló la asamblea ciudadana y el movimiento social por Aysén, que agrupa a diversas organizaciones sociales, podemos destacar: 1) la rebaja sustancial de los combustibles; leña, gas, petróleo, parafina, bencina; 2) salud de calidad; 3) equidad laboral; 4) participación ciudadana vinculante; 5) empoderamiento de la pesca artesanal regional; 6) subsidio al transporte e integración física; 7) regionalización de recursos naturales; 8) universidad estatal regional.

\subsection{Magallanes: una identidad histórica de lucha}

El conflicto tuvo sus inicios en el año 2009 en el Gobierno de Bachelet, cuando dirigentes gremiales de Magallanes denunciaron por primera vez el alza histórica del gas domiciliario y comercial. A pesar de que estas acusaciones se desmintieron, se realizaron diversas movilizaciones a fines de ese año.

En el año 2010, el Gobierno de Sebastián Piñera decidió aumentar la tarifa del gas con el argumento de reducir la diferencia entre el precio del gas subsidiado que cobra ENAP a la distribuidora Gasco Magallanes y los valores del mercado internacional. Esto fue denunciado como un acto injusto, puesto que el $75 \%$ de la producción total del gas extraído en la región es vendido a un menor precio a la empresa transnacional "Methanex», de capitales canadienses. Esto desató las movilizaciones en las principales ciudades de la región, donde se convocó a un paro indefinido que comenzó el 11 de enero. La demanda principal del movimiento era poner fin a la ley de la tarifa del gas, 
que concluyó en un acuerdo de alza del gas en un 3\% y un aumento de dieciocho mil subsidios a las familias más pobres de la región (Penaglia et al., 2016).

\section{LA RESPUESTA DEL BLOQUE EN EL PODER}

\section{LA CONCERTACIÓN SIENTE EL GOLPE Y BUSCA RECONSTRUIRSE: EL ORIGEN DE LA NUEVA MAYORÍA Y LA RESPUESTA A LOS CONFLICTOS REGIONALES}

La derrota electoral del 2010 y el estallido social del 2011 hicieron reemerger el espíritu autoflagelante en la Concertación. En la CEP de junio-julio de 2011 la Concertación —ahora como oposición — recibía solo un 16\% de aprobación y un $53 \%$ de rechazo, lo que tampoco se traducía en un apoyo al oficialismo que solo contaba con un $26 \%$ de aceptación y un $53 \%$ de rechazo.

Es en este contexto en el que la Concertación buscó revertir su rechazo apostando a un segundo periodo presidencial de Michelle Bachelet, quien habiendo terminado su primer mandato con buena aprobación ciudadana, se retiró de la política contingente para presidir ONU mujer, quedando aislada del rechazo. Pero para hacer frente a la crisis de legitimidad, la Concertación además apostó por tres aspectos para afrontar lo que se denominó «nuevo ciclo»: coalición, personajes y proyecto. De este modo, en primer lugar, se puso fin a la Concertación para dar paso a la Nueva Mayoría, lo que incluyó la incorporación del Partido Comunista. A ello se sumó el control de la agenda por parte de políticos vinculados a los «autoflagelantes» y el progresismo, lo que implicó el retiro paulatino de los «autocomplacientes». Esto se evidenció además en un cambio generacional de los actores políticos (ejemplo: Generación 90). Finalmente, las señales políticas de giro a la «izquierda» (incorporación PC y conducción «autoflagelante») se tradujeron en un «renovado» proyecto materializado en el programa de campaña, que contenía tres reformas prioritarias: 1) Reforma educacional, incorporando demandas del movimiento estudiantil como fin al lucro, gratuidad en educación superior y desmunicipalización; 2) Nueva Constitución con un proceso participativo; 3) Reforma tributaria del $3 \%$ del PIB con «equidad», para que «los que ganan más aporten más», lo que se traduciría principalmente en aumento del impuesto a empresas, fortalecimiento de competencias de fiscalización de Servicio de Impuestos Internos y perfeccionamiento de los mecanismos antielución.

Además de estos tres pilares, el programa consideraba una reforma laboral para el fortalecimiento sindical, lo que contemplaba huelga efectiva sin 
reemplazo, titularidad sindical y fin al multirut; y en lo valórico, matrimonio igualitario y ley de aborto en casos de violación, inviabilidad del feto o riesgo de vida de la madre.

En lo relativo a descentralización, para hacerse cargo del ciclo de protestas regionales ${ }^{10}$, dentro de las medidas prioritarias para los primeros 30 días, se conformó la Comisión Asesora Presidencial en Descentralización y Desarrollo Regional para elaborar una propuesta integral para modificar el excesivo centralismo chileno, la postergación de los territorios subnacionales, y principalmente, revertir y procesar la creciente conflictividad regional. Por esta razón, se nombraron a 33 comisionados, la gran mayoría de regiones, liderados por Esteban Valenzuela y Heinrich Von Baer, históricos regionalistas. La comisión también integró al excandidato presidencial regionalista Ricardo Israel y a actores claves de los movimientos regionales de los últimos años: Esteban Velásquez Alcalde de Calama y miembro activo de ese movimiento, Miriam Chible, regionalista de Aysén y dirigente del movimiento de Patagonia sin Represas; y al exsenador de Magallanes Pedro Muñoz, que si bien no fue un actor clave de ese movimiento, como miembro de la Comisión recibió el apoyo de miembros de la asamblea ciudadana de Magallanes como Marcela Baratelli. Para integrar las demandas político-regionalistas-mapuche también se incluyó en la Comisión a José Marimán, influyente intelectual ligado al partido político Wallmapuwen.

La Comisión funcionó de abril a septiembre del año 2014 a través de 5 grupos temáticos: 1) Descentralización Política, 2) Descentralización Administrativa, 3) Descentralización Fiscal, 4) Fortalecimiento de Capacidades Locales, 5) Participación Ciudadana y Control Democrático.

Para realizar un enfoque "participativo", la Comisión llevó a cabo 15 diálogos ciudadanos en todas las regiones del país, instancias donde se expresaron las distintas ideas, demandas y propuestas de los actores de cada región,

10 Si bien el ciclo de protestas de mayor visibilidad sucedió durante el gobierno de Sebastián Piñera, los movimiento no fueron procesados durante su mandato presidencial, teniendo solo respuestas parciales: en el caso de Calama a través del Fondo de Desarrollo del Norte y el proyecto Calama Plus; en Magallanes se estableció una ley de tarificación del gas sin regularse legalmente; finalmente, para el caso de Aysén se establecieron mesas de negociación parciales en torno a zonas extremas, ley de pesca y otras reformas que no vieron la luz o fueron fuertemente cuestionadas por el movimiento social. Por ello, durante las elecciones presidenciales del 2013 el tema se instaló en la agenda, existiendo incluso un candidato regionalista (Ricardo Israel). En este contexto, y teniendo como «inspiración» el «nuevo ciclo», la Nueva Mayoría, a través del programa de gobierno de Bachelet, buscó hacerse cargo de solucionar la conflictividad. 
participando alrededor de 4000 personas (Informe Comisión Asesora Presidencial para la Descentralización y Desarrollo Regional, 2014). Adicionalmente la Comisión habilitó una página web para el envío de propuestas ciudadanas y la transmisión de sesiones a través de streaming, a la vez que, como declara el informe, se recibieron en audiencia a distintas organizaciones públicas y privadas, ONG, partidos políticos, think tank, organizaciones sociales, entre otros. En suma, la Comisión declara haber recibido más de 3000 propuestas.

El proceso de estudio mediante el que se buscó determinar el tránsito de lo social a la política institucional y la agenda gubernamental contó de cuatro momentos:

1. La fase conflictiva, la que, como se detalló anteriormente, ocurrió principalmente en el periodo 2011-2013, y del que se desprendió un número de demandas regionales.

2. Los diálogos ciudadanos desarrollados en el marco de la comisión en todas las regiones, espacio en el que gran parte de los actores participantes de los movimientos regionales pudieron expresar demandas en cada uno de los cinco grupos de trabajo.

3. Informe final de la comisión asesora presidencial. Para ello se analizó el porcentaje de las propuestas surgidas en los diálogos ciudadanos que fue incorporado en el informe final. Para ello, como detalla la siguiente tabla, se clasificaron las demandas ciudadanas en tres categorías.

Tabla 2. Clasificación cumplimiento de demandas ciudadanas

\begin{tabular}{ll}
\hline \multicolumn{1}{c}{ Categoría } & \multicolumn{1}{c}{ Explicación } \\
\hline Sí & Se incorpora la propuesta en un $100 \%$ \\
\hline No & No se incorpora la propuesta \\
\hline Parcialmente & Se incorpora parte de la propuesta \\
\hline
\end{tabular}

Fuente: elaboración propia.

4. La agenda gubernamental, en la que se analizó qué porcentaje del informe y las demandas ciudadanas incorporó el Gobierno, y qué porcentaje se ha concretado en proyectos de ley o programas durante el mandato de Michelle Bachelet. Esto se analizó con cuatro categorías. 
Tabla 3. Clasificación incorporación de informe y demandas ciudadanas al Gobierno

\begin{tabular}{ll}
\hline \multicolumn{1}{c}{ Categoría } & \multicolumn{1}{c}{ Explicación } \\
\hline Sí & Se incorpora la propuesta en un $100 \%$ como proyecto de ley \\
\hline No & No se incorpora la propuesta \\
\hline Parcialmente & Se incorpora parte de la propuesta como proyecto de ley \\
\hline En agenda & $\begin{array}{l}\text { Se anuncia mediáticamente o en reuniones a los actores } \\
\text { involucrados que los contenidos serán incorporados a un } \\
\text { proyecto de ley, sin que ello se haya materializado al momento } \\
\text { del estudio (por lo que más allá del anuncio, se desconocen los } \\
\text { contenidos). }\end{array}$ \\
\hline
\end{tabular}

Fuente: elaboración propia.

Cada una de las demandas fue comparada con las acciones que ha emprendido el Gobierno de la Nueva Mayoría en relación a la materia. Este proceso ha implicado:

1. El estudio de los proyectos de ley, seguimiento del debate parlamentario y entrevistas con informantes claves de Gobierno.

2. Los datos se han cotejado a través de tres grupos de discusión durante 2015-2016 en talleres de análisis de coyuntura en el marco de observatorio de conflicto territorial.

3. Finalmente, se han realizado entrevistas y seguimiento con los miembros de la Comisión Asesora Presidencial en Descentralización y Desarrollo Regional, quienes a su vez, durante su funcionamiento, agruparon las propuestas en diez ejes prioritarios.

\section{LA INCLUSIÓN DE LAS DEMANDAS CIUDADANAS EN LA AGENDA GUBERNAMENTAL DE BACHELET}

El proceso político desde el movimiento a la agenda gubernamental es combinado. Parte del movimiento se canalizó en las asambleas o a través de comisionados vinculados a los principales conflictos regionales, a la vez que, como un mecanismo paralelo a la comisión, siguieron ocurriendo negociaciones y trabajos entre movimiento y Gobierno, como el Plan Especial de Desarrollo de Zonas Extremas.

Este análisis permitirá indagar cuán profundo es el cambio que puede tener una propuesta desde su origen, y evaluar la efectividad de los mecanismos de participación establecidos por el Gobierno. 
A continuación se hará un análisis de las 45 principales propuestas elaboradas por la ciudadanía en los diálogos regionales de la comisión, clasificándolas por grupo temático, según la metodología antes detallada.

Tabla 4. Grupo 1: Descentralización Politica

\begin{tabular}{lcc}
\hline \multicolumn{1}{c}{ Principales demandas en diálogos ciudadanos } & Comisión & $\begin{array}{c}\text { Incorporado } \\
\text { a la agenda } \\
\text { de Gobierno }\end{array}$ \\
\hline Asamblea Constituyente & Parcialmente & Parcialmente \\
\hline Mecanismos de Democracia Directa vinculantes & Sí & No \\
\hline Estatutos Regionales para territorios aislados & Sí & Parcialmente \\
\hline Elección de intendentes & Sí & Si \\
\hline Partidos Regionales & Sí & Parcialmente \\
\hline Educación Cívica & Sí & En agenda \\
\hline Limitar reelecciones & Sí & Sí \\
\hline $\begin{array}{l}\text { Región de la Araucanía Plurinacional con estatuto } \\
\text { propio y cuota a mapuches de poder }\end{array}$ & Sí & No \\
\hline
\end{tabular}

Fuente: elaboración propia.

De las ocho principales demandas de los diálogos ciudadanos, siete tuvieron correspondencia con las medidas propuestas en el informe final de la Comisión (aunque tres de ellas incluidas en el grupo 5: Mecanismos de Democracia Directa, Partidos Políticos Regionales y Educación Cívica).

A su vez, dentro de las propuestas incorporadas, dos de ellas fueron más allá que lo expresado en los diálogos ciudadanos. Tales son los casos de «Elección de Intendentes», para lo que la Comisión fijó como plazo el 2016; y «Estado Plurinacional y cuotas indígenas», donde la Comisión propuso además un Estatuto Regional propio para la Región de la Araucanía (con posibilidad de ampliación a otros territorios), incorporando, además de cuotas y reconocimiento multicultural, la existencia de grados de autodeterminación.

En cuanto a las propuestas aceptadas "parcialmente», se encuentra "asamblea constituyente», ya que en las medidas del grupo 5 se detalla «elaborar a mediano plazo una Nueva Constitución, democrática, que renueve el orden institucional chileno, iniciando para ello un proceso participativo, que involucre tanto a la ciudadanía como a los actores locales y regionales» (Comisión Asesora Presidencial en Descentralización y Desarrollo Regional, 2014: 99). 
Finalmente, la eliminación de cargos de confianza regional asignados desde el nivel central no fue considerada en el Informe.

En suma, de las propuestas ciudadanas, un $87,5 \%$ tuvo correspondencia con las medidas del informe de la comisión, un 12,5\% con aceptación parcial.

Por su parte, en lo que corresponde a la incorporación de las medidas ciudadanas a la agenda gubernamental, solo dos de las propuestas han llegado a la agenda legislativa, siendo las más destacada la elección de intendentes. El proyecto consagrado en los Boletines 9.834-06, 10.330-06, 10.422-06 y 10.443-06 consigna la elección del Ejecutivo Regional — llamado Gobernador Regional - y se crea la figura de "delegados presidenciales» — en sustitución de gobernadores- . De este modo, la reforma constitucional modifica —entre otras cosas- el artículo 112, señalando:

El gobernador regional será elegido por sufragio universal, en votación directa, por simple mayoría, y durará cuatro años en el ejercicio de sus funciones, y podrá ser reelegido por una sola vez.

Sin embargo, el proyecto genera bastantes críticas, ya que si bien propone la elección de la autoridad regional, no establece plazos para tal elección y deja abierto a una ley — aun no propuesta — la reglamentación de tal elección.

Por otro lado, establece dentro de sus funciones, además de prescindir del Gobierno regional, «ejercer las funciones de coordinación, supervigilancia o fiscalización de los servicios públicos que dependan del Gobierno Regional o se relacionen con éste, en su caso», la vez que crea la figura de «delegados presidenciales», autoridad no electa de exclusiva confianza del presidente, sobre quien recaerá la «supervigilancia y coordinación de los servicios públicos existentes en la provincia que no dependan del Gobierno Regional», agregando que "tratándose de la provincia asiento de la capital regional, al delegado provincial le corresponderá además la supervigilancia y coordinación de los servicios públicos con presencia en el nivel regional, y que no dependan del Gobierno regional; así como de los demás delegados provinciales de la región respectiva».

Este elemento, como veremos más adelante -ante una ley de traspaso de competencia débil que mantendrá la mayoría de servicios públicos dependientes del poder central-, implica que la autoridad electa sea más bien decorativa.

Respecto a otras materias planteadas en los diálogos ciudadanos, tres medidas han sido incorporadas parcialmente: asamblea constituyente, que se ha reemplazado por un "proceso constituyente» con «participación» de la ciudadanía no vinculante, dejando para el próximo Gobierno la decisión respecto al mecanismo.

Por otro lado, a pesar de que fue aprobada la ley 20 840, que sustituye el sistema binominal, limita la reelección de autoridades y permite la creación de 
partidos regionales ${ }^{11}$; en el estudio este punto fue considerado como parcialmente logrado, ya que si bien la ley permite la creación de partidos regionales, estos son limitados en su financiamiento y con altos requisitos y barreras de constitución, lo que los vuelve inexistentes en la práctica.

Finalmente, en cuanto a la creación de estatutos regionales para territorios, el Gobierno ha considerado específicamente el caso de Isla de Pascua y no de otras zonas como Araucanía - hacia donde estaba orientada la propuesta ciudadana y de la comisión.

En síntesis, el Gobierno incorporó un 25\% de las demandas, parcialmente un $37,5 \%$, en agenda un $12,5 \%$ y no incorporó el $25 \%$.

\section{Tabla 5. Grupo 2: Descentralización Administrativa}

\begin{tabular}{lcc}
\hline \multicolumn{1}{c}{ Principales demandas en diálogos ciudadanos } & Comisión & $\begin{array}{c}\text { Incorporado } \\
\text { a la agenda } \\
\text { de Gobierno }\end{array}$ \\
\hline $\begin{array}{l}\text { Creación de Gobiernos metropolitanos con } \\
\text { intendente electo y consejo de alcaldes }\end{array}$ & Sí & Parcialmente \\
\hline $\begin{array}{l}\text { Servicios públicos de carácter regionales, con } \\
\text { capacidad resolutiva, funciones, presupuestos y } \\
\text { representación provincial. }\end{array}$ & Sí & Parcialmente \\
\hline $\begin{array}{l}\text { Traspasos de competencias a las municipalidades } \\
\text { incorporando más recursos y capacidades técnico- } \\
\text { profesionales. }\end{array}$ & Sí & Parcialmente \\
\hline $\begin{array}{l}\text { Mayores atribuciones de los consejeros regionales: } \\
\text { entre otras, capacidad de elaborar proyectos de ley } \\
\text { al Parlamento. }\end{array}$ & Sí & No \\
\hline $\begin{array}{l}\text { Mejorar la coordinación de los servicios públicos } \\
\text { en la focalización de recursos considerando la } \\
\text { realidad y diversidad territorial. }\end{array}$ & Sí & Sí \\
\hline $\begin{array}{l}\text { Descentralización intrarregional de los servicios } \\
\begin{array}{l}\text { Perfeccionamiento y actualización de instrumentos } \\
\text { de planificación territorial }\end{array}\end{array}$ & Sí & No \\
\hline $\begin{array}{l}\text { Potestad reglamentaria regional amplia vinculada } \\
\text { con aspectos financieros y administrativos, con } \\
\text { traspaso de atribuciones al Consejo Regional. }\end{array}$ & Sí & No \\
\hline
\end{tabular}

Fuente: elaboración propia.

11 Lo que se debió al acuerdo entre el gobierno y los parlamentarios independientes. 
De las ocho demandas ciudadanas en torno a descentralización administrativa, siete tuvieron correspondencia con lo propuesto por la Comisión, destacando la creación de cuatro Direcciones dependientes de cada Gobierno Regional «encargadas de materializar las políticas y planes regionales vía la ejecución de programas y proyectos específicos. Estas son: a) Fomento Productivo e Innovación; b) Desarrollo Social; c) Infraestructura, Habitabilidad, Desarrollo Urbano, Transporte y Medio Ambiente, y d) Educación, Cultura, Ciencia y Tecnología. Esas direcciones se conformarán con el traspaso de las actuales direcciones regionales de servicios como CORFO, INDAP, SERVIU, Vialidad, SENCE, FOSIS y CNCA, entre otros» (Comisión Asesora Presidencial en Descentralización y Desarrollo Regional, 2014: 39). A su vez, el proceso de traspaso de competencias incluyó el ámbito municipal, criterios de diversidad territorial y la incorporación de mínimos en cuanto a recursos humanos, financieros y administrativos.

Por otro lado, el Gobierno de Michelle Bachelet, el 16 de enero de 2015, envió una indicación sustitutiva al proyecto de ley 19157 elaborado en el Gobierno anterior de Sebastián Piñera sobre Gobierno y Administración regional, profundizando la regionalización del país (Boletín 7963-06).

El texto incorpora alguna de las demandas ciudadanas y propuestas de la Comisión en lo relativo a traspaso de competencias, para ello define tres áreas en las que se pueden realizar transferencias: ordenamiento territorial, fomento de las actividades productivas y desarrollo social y cultural ${ }^{12}$.

El proyecto propone la creación de tres nuevas divisiones: fomento a la industria, infraestructura y transporte, y desarrollo social y humano. Permite a su vez modificar servicios públicos o suprimirlos, a la vez que incorpora nuevos instrumentos de ordenamiento territorial y la capacidad de coordinación intraterritorial a través de convenios de programación.

Sin embargo, el elemento central de diferenciación respecto a las propuestas ciudadanas y las medidas recomendadas por la Comisión es la no incorporación de potestad reglamentaria en los Gobiernos Regionales.

En esta línea, la propuesta de la Comisión, al definir al Estado chileno como descentralizado, define algunos principios como: autonomía; autogobierno regional y municipal; prohibición de tutela del Gobierno central en las atribuciones regionales y de los Gobiernos regionales respecto a las atribuciones municipales (Comisión Asesora Presidencial en Descentralización y Desarrollo Regional, 2014: 29). A su vez, incluye un conjunto de «competencias constitucionales exclusivas», entre las que destaca, además del uso de los

12 Respecto a la propuesta de la comisión no incluye innovación, infraestructura, desarrollo urbano, educación, ciencia y tecnología. 
instrumentos de planificación y ordenamiento territorial, «el ejercicio de facultades normativas en el ámbito de su competencia. El Consejo Regional ejercerá la potestad reglamentaria en el ámbito de ejecución de las leyes que regulan sus competencias exclusivas, compartidas o delegadas. Esta competencia reglamentaria exclusiva es parte de sus competencias constitucionales, sin necesidad de habilitación legal previa» (Comisión Asesora Presidencial en Descentralización y Desarrollo Regional, 2014: 36). A su vez el texto incluye «iniciativa de ley en materias de su competencia».

De esta forma, la propuesta de traspaso de competencias presentada por el Gobierno es mucho más acotada y no descentraliza la gran mayoría de los servicios propuestos en los diálogos ciudadanos y por la comisión.

En suma, para este grupo las medidas de la Comisión contienen el $85,7 \%$ de las principales demandas ciudadanas, y parcialmente el $12,5 \%$; mientras que el Gobierno ha incorporado en su agenda legislativa el $25 \%$, no incorpora el $37,5 \%$, mientras en el $25 \%$ lo realiza de manera parcial, como es el caso de traspaso de competencias y creación de Gobiernos metropolitanos con intendente electo, además de potestades reglamentarias y legales.

El caso más dramático de distanciamiento entre las demandas ciudadanas, medidas de la Comisión y agenda gubernamental ocurre en torno a Descentralización Fiscal. Mientras las demandas ciudadanas estudiadas en secciones anteriores apuntaban a "nacionalización del cobre y el agua» (Calama) o "soberanía sobre los recursos naturales» (Aysén), en la expresión de los diálogos ciudadanos las propuestas se transformaron en medidas redistributivas: revisar el sistema impositivo, aumento de tasas de impuesto a sector extractivista y contaminante, aumento de recursos con justicia territorial. Con este ajuste de las propuestas ciudadanas, existió un $84,6 \%$ de correspondencia entre lo expresado en los diálogos y el informe final de la Comisión, mientras solo quedaron fuera las propuestas de IPC regionalizado y la creación de fondos medioambientales para el cuidado de áreas verdes y el desarrollo del turismo.

Sin embargo, al estudiar el tránsito a la agenda gubernamental, se observa que ninguna medida fue incorporada totalmente y un $77,9 \%$ ha sido excluido del debate. Esto incluye todo lo relativo a nuevos impuestos (royalty a toda explotación de recursos renovables y no renovables, revisión de tasas de excepción tributaria e impuestos a ductos y cables eléctricos). Por otra parte, las propuestas sobre aumento de recursos como el Fondo de Convergencia y Ley de Rentas Regionales se excluyeron parcialmente $-\mathrm{o}$ se han modificado por planes piloto. 
Tabla 6. Grupo 3: Descentralización Fiscal

\begin{tabular}{|c|c|c|}
\hline Principales demandas en diálogos ciudadanos & Comisión & $\begin{array}{l}\text { Incorporado } \\
\text { a la agenda } \\
\text { de Gobierno }\end{array}$ \\
\hline Tributación en la región y no en su casa matriz & Sí & No \\
\hline $\begin{array}{l}\text { Aumento del fondo común municipal, sobre todo } \\
\text { en zonas extremas }\end{array}$ & Sí & No \\
\hline Revisión de las leyes de excepción tributaria & Sí & No \\
\hline $\begin{array}{l}\text { Creación del fondo de conservación de áreas } \\
\text { silvestres protegidas y desarrollo del turismo } \\
\text { sustentable }\end{array}$ & No & No \\
\hline $\begin{array}{l}\text { Royalty a las empresas que explotan recursos } \\
\text { naturales renovables y no renovables, con fines de } \\
\text { lucro y que sean incorporados al fondo regional }\end{array}$ & Sí & No \\
\hline $\begin{array}{l}\text { Creación de rentas regionales para la equidad } \\
\text { territorial }\end{array}$ & Sí & No \\
\hline Fondo de convergencia territorial para la equidad & Sí & Parcialmente \\
\hline $\begin{array}{l}\text { Impuestos verdes en beneficio de las comunas } \\
\text { donde están ubicadas las empresas contaminantes }\end{array}$ & Sí & No \\
\hline $\begin{array}{l}\text { Ley Espejo: que los recursos gastados en la Región } \\
\text { Metropolitana sean replicados en regiones en } \\
\text { trenes e infraestructura en general }\end{array}$ & Sí & No \\
\hline $\begin{array}{l}\text { Impuestos de servicios portuarios en beneficio de } \\
\text { las ciudades-puertos }\end{array}$ & Sí & En agenda \\
\hline Impuestos a centrales eléctricas de beneficio local & Sí & $\begin{array}{c}\text { Sólo fondo } \\
\text { vecinal }\end{array}$ \\
\hline $\begin{array}{l}\text { Creación de la tasa de impuesto municipal por } \\
\text { ductos, cables y antenas }\end{array}$ & Sí & No \\
\hline IPC regionalizado & No & No \\
\hline
\end{tabular}

Fuente: elaboración propia.

Esto, a juicio del Gobierno, se debe principalmente a la desaceleración económica, que ha implicado una restricción presupuestaria y un freno a 
muchas de las reformas del programa, a la vez que a los grandes problemas que tuvo la nueva mayoría con la reforma tributaria, que ocasionó un fuerte enfrentamiento con la derecha política y económica - y en muchos casos, al interior de la misma nueva mayoría.

De esta manera, la intención de la Comisión de transitar de un $18 \%$ a un 35\% de gasto subnacional autónomo para el año 2020 (Comisión Asesora Presidencial en Descentralización y Desarrollo Regional, 2014: 58) en la actualidad parece totalmente inviable.

Tabla 7. Grupo 4: Fortalecimiento de capacidades locales y regionales

\begin{tabular}{lcc}
\hline \multicolumn{1}{c}{ Principales demandas en diálogos ciudadanos } & Comisión & $\begin{array}{c}\text { Incorporado } \\
\text { a la agenda } \\
\text { de Gobierno }\end{array}$ \\
\hline $\begin{array}{l}\text { Fondo especial regional descentralizado que } \\
\text { permita generar incentivos para atraer y retener } \\
\text { capital humano avanzado nacional e internacional. }\end{array}$ & Sí Parcialmente \\
\hline $\begin{array}{l}\text { Incentivo a la creación y desarrollo de } \\
\text { organizaciones y programas de emprendimiento, } \\
\text { que potencie que los propios profesionales de } \\
\text { la región puedan generar nuevas propuestas } \\
\text { para atender los requerimientos y necesidades } \\
\text { regionales. }\end{array}$ & & Parcialmente \\
\hline $\begin{array}{l}\text { Reintegrar el patrimonio, cultura e historia } \\
\text { regional a los currículums educacionales. Política } \\
\text { regional de intervención integral en la formación } \\
\text { básica y media; en formación de profesores. }\end{array}$ & & \\
\hline $\begin{array}{l}\text { Promover la innovación a través de la } \\
\text { descentralización del programa Explora de } \\
\text { CONICYT para que con fondos regionales y a } \\
\text { través de convenios con el mismo CONICYT } \\
\text { se cultive el valor de las ciencias y la innovación } \\
\text { en los colegios de la región y las organizaciones } \\
\text { comunitarias. }\end{array}$ & & \\
\hline
\end{tabular}

Fuente: elaboración propia.

De las demandas expresadas en los diálogos ciudadanos en torno a capacidades locales, el $100 \%$ fue incorporado y potenciado en las medidas de la 
Comisión —a pesar de ser medidas mayormente genéricas—, destacando, por ejemplo, los «sistemas regionales de gestión de capital humano para el desarrollo de comunas y regiones», que incluye la formación de capital humano con pertenencia regional a través de la renovación del currículum escolar y la formación superior con enfoque en el desarrollo endógeno (Comisión Asesora Presidencial en Descentralización y Desarrollo Regional, 2014: 77). A su vez, las medidas van más allá de la demanda ciudadana en cuanto a la descentralización del programa Explora de CONICYT, ya que propone la creación de una institucionalidad regional descentralizada para la ciencia, tecnología e innovación - lo que además va en correspondencia con el traspaso de competencias.

Por su parte, el Gobierno no ha incorporado totalmente ninguna de estas medidas en agenda, haciéndolo solo parcialmente en lo relativo a la creación de innovaciones y emprendimientos regionales, además del fondo para la atracción de capital humano avanzado a las regiones como el programa Explora, aunque muchos de estos programas existían anteriormente.

Finalmente, de las demandas ciudadanas expresadas en los diálogos del grupo 5, un $41,7 \%$ tuvo correspondencia con lo planteado por la Comisión (aunque varias propuestas ciudadanas del grupo 1 fueron aceptadas por el grupo 5). Entre ellas destacan la «participación directa en los asuntos de interés regional y local», a través de referéndum revocatorio de mandato, plebiscito y referéndum revocatorio de reglamentos, los tres mecanismos con capacidad de convocatoria ciudadana, vinculantes y con financiamiento.

En cuanto a la solicitud de creación de un órgano colegiado de la sociedad civil a nivel regional, este fue acogido, pero solo como un instrumento consultivo y no resolutivo. Finalmente, fue considerada, "parcialmente», la obligatoriedad de la participación ciudadana en los instrumentos de planificación regional y local, ya que, si bien dentro de las propuestas de la Comisión se incluye «consagrar el derecho constitucional a la participación en los tres niveles del Estado» (local, regional y central), no se talla explícitamente la obligatoriedad de esta. 
Tabla 8. Grupo 5: Participación Ciudadana y Control Democrático

\begin{tabular}{|c|c|c|}
\hline Principales demandas en diálogos ciudadanos & Comisión & $\begin{array}{l}\text { Incorporado } \\
\text { a la agenda } \\
\text { de Gobierno }\end{array}$ \\
\hline Diagnósticos participativos & No & No \\
\hline $\begin{array}{l}\text { Plebiscito ante conflictos intendente-consejo } \\
\text { regional }\end{array}$ & Sí & No \\
\hline $\begin{array}{l}\text { Obligatoriedad de participación ciudadana e } \\
\text { información y difusión de sus propuestas en el caso } \\
\text { de instrumentos de planificación regional y local }\end{array}$ & Parcialmente & No \\
\hline $\begin{array}{l}\text { Instalar los «diálogos comunales», o los cabildos } \\
\text { abiertos, espacio de encuentro que comunica } \\
\text { directamente a los representantes con los } \\
\text { representados }\end{array}$ & No & No \\
\hline $\begin{array}{l}\text { Sistema de control ciudadano de recursos públicos } \\
\text { y monitoreo de fondos públicos con participación } \\
\text { ciudadana }\end{array}$ & No & No \\
\hline $\begin{array}{l}\text { Modificar la ley } 20500 \text { para que los COSOC sean } \\
\text { convocados automáticamente y creación de un } \\
\text { COSOC regional }\end{array}$ & Parcialmente & En agenda \\
\hline Programa Nacional de Educación Cívica & Sí & En agenda \\
\hline $\begin{array}{l}\text { Modificación de ley electoral para exigir un } \\
\text { programa a cada postulante a alcalde para un } \\
\text { mejor control ciudadano }\end{array}$ & Sí & No \\
\hline $\begin{array}{l}\text { Creación de un órgano colegiado de la sociedad } \\
\text { civil a nivel regional para la participación } \\
\text { ciudadana con poder resolutivo }\end{array}$ & Parcialmente & No \\
\hline $\begin{array}{l}\text { Creación de escuelas de formación para líderes y } \\
\text { dirigentes sociales }\end{array}$ & Sí & Parcialmente \\
\hline $\begin{array}{l}\text { Defensor del Pueblo descentralizado desde su } \\
\text { creación, «ciudadano fiscalizador» }\end{array}$ & Parcialmente & En agenda \\
\hline $\begin{array}{l}\text { Instauración del Referéndum revocatorio en } \\
\text { autoridades ejecutivas (alcaldes, intendentes, entre } \\
\text { otros) }\end{array}$ & Sí & No \\
\hline
\end{tabular}

Fuente: elaboración propia. 
En cuanto a la inclusión en la agenda de Gobierno, un 8,3\% fue parcialmente incorporado en lo relativo a Escuelas para Dirigentes Sociales que creó la División de Organizaciones Sociales (DOS) con 100 escuelas en el 2014 para capacitar a 15000 dirigentes. Por su parte, un $25 \%$ se encuentra en agenda y ha sido anunciado, pero aún no se conoce el contenido y extensión de los proyectos. Tal es el caso del Defensor del Pueblo, la inclusión de educación cívica y el mejoramiento de la Ley 20.500, tres aspectos declarados en el programa presidencial y comprometido por la Secretaría General de Gobierno. Finalmente, un $66,6 \%$ no fue incorporado.

\section{REFLEXIONES FINALES: ANÁLISIS GLOBAL DE LOS RESULTADOS}

Como se ha estudiado en el presente trabajo, las demandas de los movimientos sociales del periodo 2011-2013 fueron procesadas por el sistema político durante el Gobierno de la Nueva Mayoría, pasando por distintas fases de «filtro» o instrumentos de dilatación- cooptación. En primer lugar, mediante la invitación de algunos actores regionales a "diálogos ciudadanos», fase en la que los actores del movimiento invitados fueron integrados en un espacio más amplio con funcionarios, organizaciones sociales, gremios, empresariado, entre otros. De esta forma, el peso relativo del movimiento social y su capacidad de incidir con sus demandas en la priorización de las propuestas de los diálogos ciudadanos pudo ser menor por los mecanismos de jerarquización y la falta de constitución de una agenda socio-política transformadora a nivel nacional. Durante esta fase, efectivamente algunos conflictos se desmovilizaron, priorizando la canalización institucional de las demandas mediante la participación al interior de la comisión.

En segundo lugar, solventado el escollo anterior, las demandas efectivamente resultantes de los diálogos ciudadanos pasaron al filtro de la Comisión. En esta fase cada grupo temático, tomando como insumo el resultado de los diálogos (de manera consultiva y no vinculante), decidió llevar —o no- las medidas al plenario de la Comisión, donde debían votar todos los comisionados. Para que un acuerdo fuera aceptado requería el voto positivo de $17 \mathrm{miem}$ bros (en un universo real de 25 comisionados en promedio), es decir, necesitaba un acuerdo de mayoría, consensuado, lo que se dificultaba a su vez por la procedencia política diversa de los miembros ${ }^{13}$.

13 Sobre la procedencia política de los comisionados, seis eran independientes de izquierda no vinculados a la Concertación-Nueva Mayoría, dieciocho militantes de la Concertación-Nueva Mayoría (seis demócrata cristianos, tres socialistas, tres del 
En tercer lugar, habiendo sido incorporadas ciertas demandas al informe final de la Comisión, resta un tercer filtro, que es que los acuerdos del informe tampoco fueron vinculantes, ante ello el Gobierno y su agenda decidió seleccionar solo algunas medidas como proyectos de ley. El resultado final de todo este proceso es:

1. Respecto a Calama, pese a tener dentro de la Comisión a uno de los líderes del movimiento Esteban Velásquez, las dos medidas más politizadas y estructurales: $5 \%$ de utilidades del cobre para la región y la nacionalización del agua, litio y cobre, no llegaron a los diálogos ciudadanos como medidas priorizadas, ni fueron propuestas por la Comisión. Menos aún se encuentran en la agenda gubernamental. El resto de las medidas fueron consideradas en la Comisión, aunque no directamente, sino a través del aumento de recursos a través del Fondo de Convergencia y Ley de Rentas Regionales (no consideradas por el Gobierno).

2. En cuanto a Magallanes, las demandas del movimiento fueron mucho más reivindicativas que en el caso de Calama. Estas sí fueron expresadas en los diálogos y principalmente han tenido un tratamiento específico de parte del Gobierno a través del Plan Especial de Desarrollo de Zonas Extremas. Las demandas del movimiento que a la fecha no se ha incorporado son sueldo mínimo diferenciado y el proyecto de tarificación del gas.

3. Finalmente, el movimiento de Aysén ha sido abordado de un modo similar al de Magallanes a través del Plan Especial de Desarrollo de Zonas Extremas, lo que ha permitido una inyección de recursos. También se anunció la creación de una Universidad Pública Regional. Sin embargo, más allá de estas medidas menores, los avances no han ido mucho más allá en lo que involucra distribución de poder. Siguen sin solución las demandas relativas a regionalización y administración soberana de los recursos naturales, democratización a través de participación ciudadana vinculante y otras de las demandas establecidas en el petitorio del movimiento. La mayoría de estas reivindicaciones más políticas, sumadas a las priorizadas en el diálogo de ciudadano de Aysén tal como Asamblea Constituyente o modificación del Sistema

Partido por la Democracia, un comunista, un radical y cuatro independientes, pero participantes de este conglomerados), cuatro independientes y nueve militantes de partidos de derecha e independientes de derecha: dos de la Unión Demócrata Independiente, tres de Renovación Nacional y cuatro independientes. 
de Evaluación Ambiental, tampoco lograron ser instadas en el informe de la Comisión pese a que en su interior se encontraba Miriam Chible, líder social de Aysén.

En suma, del petitorio de los movimientos regionales ha sido una mínima fracción lo que ha llegado a impactar en la agenda legislativa de la nueva mayoría. A su vez, como se señaló en la sección anterior, pese a que los diálogos ciudadanos fueron el primer «filtro», aun considerando el resultado de estos como las «únicas y legítimas aspiraciones populares», tampoco impactaron mayormente en la agenda legislativa. Tal como muestran los datos integrados del gráfico 3, solo un $15,5 \%$ de las demandas fue considerada en la agenda gubernamental, mientras un $55,5 \%$ no.

\section{Gráfico 3. Porcentaje de elementos considerados del petitorio de los movimientos sociales}

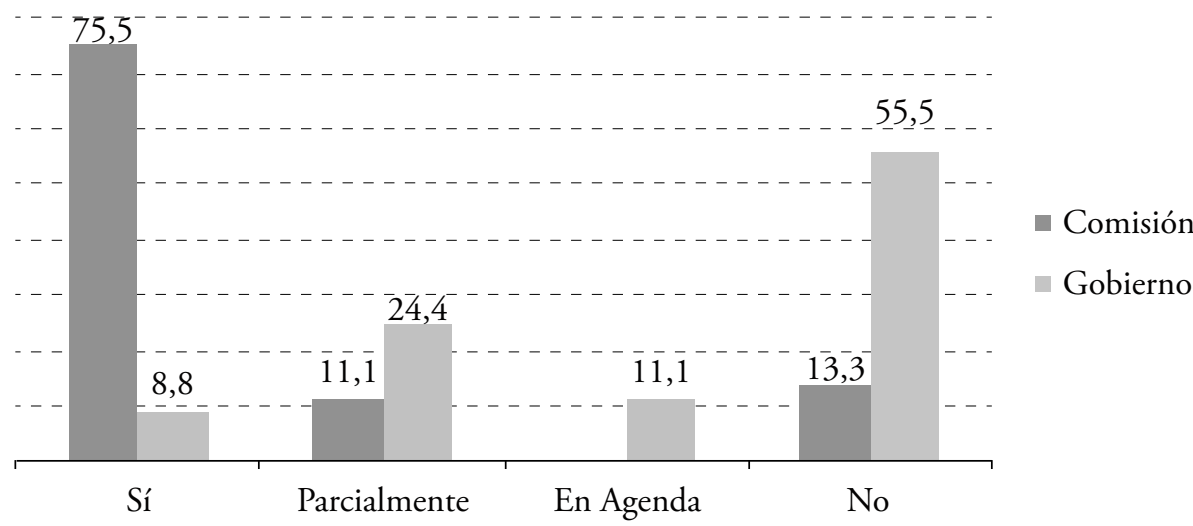

Fuente: elaboración propia.

Finalmente, frente a la discusión de fondo, ¿cooptación autoritaria o perspectiva transformadora?, a la luz de los resultados la respuesta se inclina hacia lo primero. Más allá de una «retórica» renovadora y transformadora de «nuevo ciclo» y nuevo vínculo entre Estado y sociedad, la coalición mantiene una hegemonía conservadora autocomplaciente de centro derecha, continuadora del modelo pinochetista.

Si bien la Nueva Mayoría se impuso en las elecciones presidenciales, obteniendo además mayoría legislativa en ambas cámaras, y en un comienzo los grupos «autoflagelantes» habían tomado el control del aparato del Estado utilizando 
un discurso refundacional ${ }^{14}$, los escándalos de corrupción ${ }^{15}$, la desaceleración económica y la baja en las encuestas llevaron a que el Gobierno, que inicialmente contaba con un claro respaldo, se empezara a resquebrajar ${ }^{16}$. Ante ello, hubo una retoma del control gubernamental de parte de los autocomplacientes.

En síntesis, las diez medidas de mayor transformación propuestas por la Comisión Presidencial, se morigeraron o rechazaron todas:

- Al gobernador regional electo se le crea una figura de delegado presidencial fuerte y se mantiene el poder de las agencias regionales en un modelo dual incremental. Esto, desde la perspectiva autocomplaciente del orden, busca evitar desde el Gobierno central perder poder y control en las regiones, a la vez que, desde una perspectiva parlamentaria, la oposición a que exista un Gobierno regional autónomo empoderado.

- Se rechazó el consenso para crear una región autónoma mapuche y se presentó un proyecto de creación de Ministerio de Asuntos Indígenas hacia el 2020; con el argumento de que 1- se debe preservar la identidad nacional; 2- poner Mapuche podría poner en riesgo el extractivismo forestal; 3- podría ser la puerta de entrada a un separatismo nacionalista. Es necesario considerar que estas políticas solo podrían

14 Con conceptos como «retroexcavadora» (para referirse a las transformaciones profundas que debían emprenderse) o «los poderosos de siempre» (para confrontarse a la derecha política y económica).

Los tres principales escándalos han sido: el caso Penta, que ha involucrado el financiamiento ilegal de campañas políticas a los partidos de derecha, principalmente la UDI; el caso Caval, que involucró al hijo de la presidenta en un aparentemente tráfico de influencias en el negocio inmobiliario y de acceso a información sobre el uso de suelos; y el caso Soquimich, donde el exyerno de Pinochet, quien además se adueñó en la dictadura de la exempresa del Estado, financió de manera irregular la campaña de Bachelet, lo que llevó a la caída del ministro del Interior Rodrigo Peńailillo (quien representaba una renovación generacional de la política).

16 Con ello, la hostilidad al programa y las reformas venía de tres lugares: de sectores autocomplacientes al interior de la Nueva Mayoría y el Gobierno (oficialismo) para hacerlas más graduales o menos intensas; de la derecha por detenerlas; de los sectores a la izquierda de la Nueva Mayoría y el Gobierno), las organizaciones populares y los movimientos sociales por profundizarlas o encontrarlas insuficientes. De este modo, las encuestas comenzaron a evidenciar el poco respaldo a las reformas, lo que se interpretó hegemónicamente solo desde la óptica de la derecha: «la ciudadanía no quería reformas». No hubo prácticamente ningún analítico o político que interpretara la falta de apoyo a las reformas desde el deseo popular por considerarlas insuficientes. 
responder a la relación íntima del poder económico y político, ya que los argumentos vulneran tratados internacionales, como 169 OIT, al no reconocerlos como un pueblo con identidad, instituciones, cultura, lengua propia y derecho consuetudinario.

- Se pospuso el traspaso de competencias sin un tribunal en el que las regiones puedan reclamar competencias, quedando el proceso a merced del Gobierno de turno, que podría crear la comisión, el sistema de evaluación y la entrega de competencias por decreto. No obstante, ante el reclamo de las bancadas regionalistas en la Cámara y el Senado e incluso la protesta de excomisionados para la descentralización, se entregó poder de coordinación metropolitano y se crearon tres nuevas divisiones en los gobiernos regionales: infraestructura-transporte, social y fomento productivo como medidas paliativas.

- Se disminuyó toda potestad territorial, ya que los Planes Regionales de Ordenamiento Territorial no son vinculantes y deben ser visados por varios ministerios. Con ello se niega la posibilidad de regiones que posean modelos alternativos de desarrollo y regulación del territorio.

- Ninguna de las medidas de participación, plebiscitos y revocatoria popular de autoridades electas ha sido considerada.

- En lo económico no se consideró dar poder a las regiones en los commons, como el agua y la tributación minera, y tampoco se envió una ley de rentas regionales, a pesar del acuerdo unánime de los comisionados. Las grandes empresas y el centralismo chileno que se expresa en el control del gasto por el Ministerio de Hacienda se opusieron a la ley de rentas territoriales argumentando que afectaría a la inversión en el contexto de contracción económica por la baja del precio del cobre en el trienio 2014-2016.

El cuadro actual de Chile y la trayectoria hecha hasta aquí evidencian la incapacidad de las dos mayores fuerzas políticas de construir un proyecto colectivo que supere la crisis y el malestar. Pese a los intentos de la Concertación de reposicionarse a partir de una retórica transformadora (nueva mayoría), la evidencia indica que el orden autocomplaciente se impuso y que el sistema político no fue capaz de procesar adecuadamente las demandas regionales, demostrando nuevamente el divorcio entre pueblo y bloque en el poder. La izquierda, fuera de las dos grandes coaliciones, cuenta actualmente con un senador de 38 y cinco diputados de 120, por lo que su peso es mínimo para modificar la agenda legislativa gubernamental. El surgimiento, no obstante, de diez partidos regionales y la politización ascendente de los movimientos 
rupturistas del modelo abren un clivaje nuevo en el que la descentralización sustantiva puede tener mayores posibilidades.

\section{Bibliografía}

Andara, A. (2007). La segunda generación de Reforma del Estado y su efecto en la administración pública local de América Latina. Provincia, 77-105.

Atria, F. (2013). La constitución tramposa. Santiago de Chile: LOM.

Benavente, D. (2007). Descentralización: la Revolución Olvidada. Temuco: Editorial UC.

Camou, A. (2010). El Discurso sobre la Crisis de Gobernabilidad de las democracias capitalistas avanzadas: Una revisión del informe de la comisión trilateral (1975-2010). Argentina: Universidad de la Plata.

Comisión Asesora Presidencial en Descentralización y Desarrollo Regional (2014). Propuesta de Política de Estado y Agenda para la Descentralización y el Desarrollo Territorial de Chile. Hacia un país desarrollado y justo (Informe Comisión Asesora Presidencial en Descentralización y Desarrollo Regional). Disponible en: https://goo.gl/aUoXtT.

Dávila, A y Penaglia, F. (2012). El sector no lucrativo chileno como una alternativa para la superación de la pobreza. Paraguay: Ediciones UNE.

Durston, J. (2012). Clientelismo político y actores populares en tres regiones de Chile. En G. Delamaza, N. Cunill Grau y A. Joignant (eds.). Nueva agenda de descentralización en Chile: sentando más actores a la mesa (pp. 369-391). Santiago de Chile: RIL Editores.

Fernández, F. (2002). La constitución del 80: enclaves autoritarios y cerrojos institucionales. En H. Concha (coord.). Sistema representativo y democracia semidirecta. Memoria del VII Congreso Iberoamericano de Derecho Constitucional.

Garcés, M. (2012). El despertar de la sociedad. Los movimientos sociales en América Latina y Chile. Santiago de Chile: LOM.

García, J. (2003). De la primera a la segunda generación de reformas del Estado en América Latina; giro ideológico y cambio conceptual. Cuadernos de Economía, 22 (38), 95-125.

Garretón, M. (2003). Incomplete Democracy. Political Democratization in Chile and Latin America. Chapel Hill: University of North Carolina Press.

- (2009). Problemas heredados y nuevos problemas en la democracia chilena. ¿Hacia un nuevo ciclo? En G. De la Fuente González (ed.). Economía, instituciones y política en Chile. Santiago: Ministerio Secretaría General de la Presidencia.

- (2013). Conflicto Estado-Sociedad y ciudadanía. Conferencia en el Instituto Igualdad, Santiago, 2 de octubre de 2013.

Gaudichaud, F. (2015). Las fisuras del neoliberalismo chileno. Trabajo, crisis de la «democracia tutelada» y conflictos de clase. Santiago de Chile: Quimantú y Tiempo robado editoras.

Gerschewski, J. (2010). The three pillars of stability. Towards an explanation of the durability of autocratic regimes in East Asia. 106th Annual Meeting of the American Political Science Association (APSA), 2-5 septiembre 2010. Washington, D.C.

Haldenwang, Ch. (1990). Hacia un concepto politológico de la descentralización del Estado en América Latina. Revista Latinoamericana de Estudios Urbano Regionales, 17 (5), 61-77. Disponible en: https://goo.gl/PEvx2m. 
Hidalgo, P. (2011). El ciclo politico de la Concertación. Santiago de Chile: Uqbar.

Isner, M. (2004). Las dos renovaciones de la izquierda chilena. Documentos-Cadal, año II, 19. Mardones, R. (2008). Descentralización: una definición y una evaluación de la agenda legislativa chilena (1990-2008). Revista Latinoamericana de Estudios Urbano Regionales, 34 (102), 39-60. Disponible en: https://doi.org/10.4067/S0250-71612008000200003.

Mayol, A. (2012). El derrumbe del modelo. La crisis de la economía de mercado en el Chile Contemporáneo. Santiago de Chile: LOM.

- (2013). Límites de la Democracia. Coloquio Golpe 1973-2013. Teatro Nacional Antonio Varas. Santiago de Chile: Lapsos-Universidad de Chile.

Monedero, J. (2012). El programa de máximos del neoliberalismo: el Informe a la Trilateral de 1975. Revista Sociología Histórica, 1 (1), 289-310.

Moulian, T. (1997). Chile Actual. Anatomía de un Mito. Santiago de Chile: LOM.

Ominami, C. (2009). El debate silenciado. Santiago de Chile: LOM.

Oppliger, M. y Guzmán, E. (2012). El malestar de Chile ¿teoría o diagnóstico? Santiago de Chile: Ril Editores.

Ortiz, E. (2015a). La ambigüedad política DC y su inclinación autoritaria. El Mostrador, 4-82015. Disponible en: https://goo.gl/qZSDHE.

- (2015b). El PS diez años después del XXVII congreso, lecciones no aprendidas. El mostrador, 28-1-2015. Disponible en: https://goo.gl/iBywRA.

Penaglia, F. (2013). Desde la matriz Estado céntrica al autonomismo: una perspectiva histórica de lo político, social e identitario. Revista Búsquedas Políticas, 2 (1), 21-36.

_ y Valenzuela, E. (2014). Rebeldía en Calama: desafío al orden centralista chileno en un contexto de boom minero. Revista Mexicana de Ciencias Politicas y Sociales, 59 (222), 161-185. Disponible en: https://doi.org/10.1016/S0185-1918(14)70214-4.

_ Valenzuela, E. y Basaure, L. (2016). Acciones colectivas territoriales en Chile, 20112013: De lo ambiental reivindicativo al autonomismo regional. Revista Latinoamericana de Estudios Urbano-Regionales, 42 (125), 225-250.

Programa de las Naciones Unidas para el Desarrollo (PNUD) (1998). Segundo Informe sobre el Desarrollo Humano: Chile 1998. PNUD.

- (2012) Desarrollo humano en Chile. Bienestar subjetivo: el desafio de repensar el desarrollo. Parte 1. PNUD

- (2014) Auditoria a la democracia. Más y mejor democracia para un Chile inclusivo. Chile: LOM.

- (2015) Desarrollo humano en Chile. Los tiempos de la politización. PNUD.

Rosales, M., Valencia, S. y Martínez, J. (2012) Descentralización del Estado y finanzas municipales en América Latina. Santiago: Editorial Universidad Bolivariana, FLACMA, CGLU.

Salazar, G. (2011). En el nombre del Poder Popular Constituyente (Chile, siglo XX). Santiago de Chile: LOM.

(2013). Movimientos sociales en Chile. Santiago de Chile: Uqbar.

— y Pinto, J. (1999). Historia Contemporánea de Chile. Santiago de Chile: LOM.

Santiso, C. (2001). Gobernabilidad democrática y política económica insular. Paradojas de las reformas de segunda generación en la Argentina de los 1990. Contribuciones, 72, 109-136.

Selznick, P. (1994). Bases de la teoría de la Organización. En X. Ballart y C. Ramió (eds.). Lecturas de Teoría de la Organización. Madrid: Ministerio para las Administraciones Públicas. 
Siavelis, P. (2009). Enclaves de la transición y democracia chilena. Revista de Ciencia Política, 29 (1), 3-21. Disponible en: https://dx.doi.org/10.4067/S0718-090X2009000100001. Thayer, L. (2011). Descentralización y desarrollo regional en Chile. Polis, 10 (30), $267-$ 287. Disponible en: http://polis.revues.org/2291; https://doi.org/10.4067/S071865682011000300013.

Tironi, E. (2002). El cambio está aquí. Santiago de Chile: Editorial Sudamericana Chilena, S. A.

- (2011). ¿Por qué no me quieren? Del Piñera way a la rebelión de los estudiantes. Santiago de Chile: Uqbar.

Troncoso, N. (2016). El post conflicto en Calama [tesina de grado]. Santiago de Chile: U. A. Hurtado.

Valenzuela, E. (1999). Alegato Histórico Regionalista. Santiago de Chile: Ediciones Sur.

- (2014). La conversión de los socialistas chilenos. Esquema de transformación politico-cultural de una élite. Desde la revolución al orden. Santiago de Chile: Editorial el Desconcierto.

- (2015). El modelo dual incremental de regionalización en Chile. Revista Iberoamericana de Estudios Municipales, 6 (11), 173-194.

Valenzuela, E., Pressacco, F., Cienfuegos, I. y Penaglia, F. (2015). Pilares necesarios para una descentralización sin cooptación del poder central: reflexiones para el proceso descentralizador chileno. Revista de Administración Pública, 49 (5), 1083-1106. Disponible en: https://doi.org/10.1590/0034-7612137403.

Valenzuela, E. y Yévenes, P. (2015). Aproximación al concepto de cooptación política: la maquinaria presicrática y sus formas. Polis, 14 (40), 469-488. Disponible en: http:// polis.revues.org/10834. 
ANEXO 1

Tabla de resumen de movimientos territoriales

\begin{tabular}{|c|c|c|c|}
\hline & Calama & Magallanes & Aysén \\
\hline $\begin{array}{l}\text { Actores } \\
\text { principales }\end{array}$ & $\begin{array}{l}\text { Asamblea ciudadana. } \\
\text { Alcalde }\end{array}$ & $\begin{array}{l}\text { Asamblea } \\
\text { ciudadana } \\
\text { Magallanes }\end{array}$ & $\begin{array}{l}\text { Movimiento social por } \\
\text { Aysén. } \\
\text { Coordinadora regional } \\
\text { anti represas Aysén. }\end{array}$ \\
\hline $\begin{array}{l}\text { Puntos } \\
\text { Centrales del } \\
\text { Petitorio }\end{array}$ & $\begin{array}{l}5 \% \text { utilidades de } \\
\text { CODELCO. } \\
\text { Compensación de } \\
400 \text { millones de } \\
\text { dólares. } \\
\text { Renacionalización del } \\
\text { agua, litio y cobre. } \\
\text { Medidas paliativas } \\
\text { por la contaminación } \\
\text { minera. } \\
\text { Más profesionales y } \\
\text { especialistas para el } \\
\text { hospital de la región. }\end{array}$ & $\begin{array}{l}\text { Sueldo } \\
\text { mínimo } \\
\text { diferenciado } \\
\text { para la región } \\
\text { de Magallanes } \\
\text { y las zonas } \\
\text { extremas. } \\
\text { Cambio al } \\
\text { proyecto de } \\
\text { ley sobre tarifa } \\
\text { del gas. }\end{array}$ & $\begin{array}{l}\text { Subsidio al combustible. } \\
\text { Salud de calidad } \\
\text { (infraestructura). } \\
\text { Equidad Laboral [11]. } \\
\text { Participación ciudadana } \\
\text { vinculante. } \\
\text { Universidad Regional } \\
\text { Pública. } \\
\text { Administración y } \\
\text { regionalización de los } \\
\text { recursos naturales. } \\
\text { Subsidio al transporte. } \\
\text { Programa de desarrollo } \\
\text { para del pequeño y } \\
\text { mediano campesinado } \\
\text { rural. }\end{array}$ \\
\hline $\begin{array}{l}\text { Tipo de } \\
\text { organización } \\
\text { predominante }\end{array}$ & Asamblea ciudadana & $\begin{array}{l}\text { Asamblea } \\
\text { ciudadana }\end{array}$ & $\begin{array}{l}\text { Asamblea de } \\
\text { organizaciones. }\end{array}$ \\
\hline Meta relato & Regionalismo & Zona extrema & $\begin{array}{l}\text { Zona extrema } \\
\text { anticentralismo. }\end{array}$ \\
\hline $\begin{array}{l}\text { Tipo de } \\
\text { movilización }\end{array}$ & $\begin{array}{l}\text { Corte de calles, } \\
\text { paralización comuna, } \\
\text { marchas. } \\
\text { Intensidad moderada } \\
\text { del conflicto. }\end{array}$ & $\begin{array}{l}\text { Paros, } \\
\text { marchas. }\end{array}$ & $\begin{array}{l}\text { Paralización regional, } \\
\text { cortes de ruta, } \\
\text { barricadas, marchas, } \\
\text { enfrentamiento con } \\
\text { carabineros. } \\
\text { Intensidad alta del } \\
\text { conflicto. }\end{array}$ \\
\hline Temporalidad & Larga & Media & Larga \\
\hline
\end{tabular}

Fuente: Penaglia et al. (2016). 